\title{
Diáspora bayfal en España: disputando la migración senegalesa murid ${ }^{1}$
}

\author{
Bayfall diaspora in Spain: \\ Contesting Senegalese Murid Migration
}

\author{
Ester Massó Guijarro \\ Departamento de Antropología Social, \\ Universidad de Granada, España \\ ester@ugr.es
}

\section{RESUMEN}

El principal objetivo de este artículo es estudiar el movimiento bayfal (bayfalismo) en el seno del muridismo, desde una perspectiva transnacional y como adscripción específicamente migratoria en la contemporaneidad. Se comparará el bayfalismo original como heterodoxia sufí en Senegal, dentro de la cofradía Muridiyya, con el caso de estudio en la diáspora migratoria en Madrid (España) y secundaria y complementariamente Granada (Andalucía, España). Se trabaja la hipótesis de que la diáspora está cambiando tanto la forma de adscripción al bayfalismo (intensificando las adhesiones, de hecho), como los contenidos identitarios en sí de esta categoría. Asimismo, se analizará cómo los elementos típicamente sufíes en el bayfalismo resultan más visibles o prevalentes frente a su condición islámica.

La metodología usada es una conjunción de etnografía y análisis bibliográfico.

Palabras clave: Bayfal; Yayfal; Diáspora; Muridiyya; Sufismo; Transnacionalismo migratorio; Globalización.

\section{SUMMARY}

The main aim of this paper is to study the Bay Fall movement (hereafter Bayfallism) within Mouridism from a transnational perspective and as a specifically migratory affiliation in contemporaneity. We compare the origins of Bayfallism within the Mouride brotherhood, as a Sufi heterodoxy in Senegal, with current case studies on the migrant diaspora in Madrid (Spain) and in a secondary and complementary manner, in Granada (Andalusia, Spain). Our hypothesis is that the diaspora is changing both allegiance to Bayfallism (with a growing number of affiliations) and the very identity contents of this category. We also analyse how the typically Sufi elements in Bayfallism are more visible or prevalent than its pure Islamic condition.

Our methodology is a conjunction of ethnography and bibliographical analysis.

Key words: Bay Fall; Yaye Fall; Diaspora; Mouridism; Muridiyya; Sufism; Migrant Transnationalism; Globalization.

\footnotetext{
${ }^{1}$ Trabajo redactado en el marco del proyecto de investigación "Libertad, convivencia e integración religiosa, social y cultural: propuestas desde el cristianismo tardoantiguo", del Plan Propio de la Universidad de Granada (2014-2016), cuya Investigadora Principal es Purificación Ubric Rabaneda. Agradezco la amable revisión del manuscrito original a Juan Antonio Estrada Díaz y Purificación Ubric Rabaneda. Dedico este artículo y el trabajo que se halla a la base a mis amigos murid, bayfal y no bayfal, que contribuyeron de forma inestimable a iluminar mi visión.
} 


\section{INTRODUCCIÓN: LA ANTINOMIA VERTEBRAL DEL BAYFALISMO}

"They are Bay-fall. They have dreadlocks to look like a lion, to show you never run away" (Savishinsky 1994: 217).

"Los bayfal... hay algunos que lo viven mucho, y hay otros que no" (interlocutora yayfal, migrante en Madrid, entrevista 02/02/2012).

La comunidad bayfal constituye una rama interna o clase específica dentro de la Muridiyya $^{2}$ que posee una peculiar idiosincrasia. Ha sido definida, interpretada, nombrada, adorada y denostada de múltiples maneras. Sus miembros, originariamente seguidores de Sheik Ibrahima Fall, mano derecha y servidor personal de Ahmadou Bamba, y de quien toman su nombre ${ }^{3}$, se encargan primordialmente de los trabajos manuales en la cofradía (cocinando y limpiando durante la celebración de un magal ${ }^{4}$, por ejemplo), lo que les libera parcialmente a su vez de rezar o estudiar el Corán en la misma medida que han de hacerlo otros murid, como si su camino de liberación y piedad hacia Dios $^{5}$ constituyera la vía del trabajo físico (kasbu, en detrimento del cultivo espiritual y/ o el rezo, amal). Pero, por otro lado, a su vez practican intensos rituales de trance religioso y se autodenominan "los más murid entre los murid", los más auténticos y entregados: igual que Fall, los más cercanos al maestro, los más esforzados y piadosos; y los que siguen, incluso, un sendero propio de tipo más esotérico, más profundamente sufí, frente a la rama exotérica murid no bayfal: el camino del corazón.

Gran número de ellos trabajan en las dahiras ${ }^{6}$ durante su periplo diaspórico precisamente en ese ejercicio de superación religiosa a través del esfuerzo material. Sin embargo, los murid no bayfal a menudo ven en ellos una excesiva relajación (con la excusa del trabajo, dicen) con respecto de ciertos deberes islámicos: de facto, los bayfal

\footnotetext{
${ }^{2}$ Sobre la Muridiyya como orden sufí islámica, ya de por sí heterodoxa en su práctica musulmana, Iniesta Vernet (2009: 33) lo resume como la oposición o el contraste entre "la daara de los sheiks y la da'wa de los jóvenes formados en el rigorismo moderno de saudíes y libios". Ver también Costa Dias (2009). Existen tres cofradías sufíes principales en Senegal: la Qadriyya, la Tijaniyya y la Muridiyya, siendo esta última la única fundada en este país y la más abundante en la diáspora (con una clara dominancia wolof). La Tijaniyya, por su parte, es la más numerosa en Senegal, seguida por la Muridiyya. Ésta fue fundada en el siglo XIX por Ahmadou Bamba, también llamado Serigne Touba (Senegal 1853-1927), hijo de un marabout de la cofradía Xaadir.

3 "Bayfal" significa literalmente "padre Fall", siendo modo habitual como se llaman amistosamente entre ellos

${ }^{4}$ Los magal son las grandes celebraciones religiosas murid por antonomasia, que suelen involucrar una comida o cena colectiva y, sobre todo, el honramiento a un líder religioso concreto. Estos eventos (lugares-momentos, los llama Guèye) son esenciales para la construcción del carisma de tales líderes (Guèye 2009: 105). Suelen estar ligados a fechas clave en el calendario musulmán, pero incluso estas fechas resultan a menudo modificadas y matizadas por las propias efemérides murid.

${ }^{5}$ El término "Dios" se usará siempre como genérico de divinidad.

${ }^{6}$ Las dahiras son las grandes agrupaciones, asociaciones o hermandades en las que se organiza la cofradía murid y, por lo general, hoy poseen un alcance transnacional. Para una revisión del estado de la cuestión sobre la Muridiya y las dahiras: Crespo Ubero (2006), Evers Rosander (2000), Guèye (2009), Jabardo Velasco (2006), Massó Guijarro (2012b), Moreno Maestro (2007), Sow (2004), en ámbito español; en ámbitos senegaleses e internacionales: Ba (2008), Babou (2002), Coumba Diop (1981), Diouf y Rendall (2000), Kane (2009), Mbaye y Nadhiri (2010) o Riccio (2008 y 2011).
} 
no solo se declaran parcialmente eximidos de los cinco rezos diarios, sino que a menudo beben alcohol y fuman hashish de modo habitual, todo ello prohibido por el Corán. Incluso la indumentaria resulta heterodoxa con respecto a otros murid, como la frecuencia en el uso de rastas, lo que ha motivado estudios comparativos entre el rastafarismo y el bayfalismo (Savishinsky 1994). Así, hoy no es extraño ver grupos de bayfal por las calles de Lavapiés, Granada o Alicante vestidos con sus coloridos trajes y cinturones, sus llamativas rastas, sus preceptivos curus (rosarios de ébano o jalambañ) en el cuello o relicarios con el rostro de Ibrahima Fall, entonando repetitivas salmodias rodeados por un delatador perfume cannábico.

Murid significa "el que desea" (Skali 2006: 28); los bayfal se autoconsideran "los que más desean" de entre los murid, pues, mientras que los taalibe (discípulos) no bayfal suelen mostrarse superiores precisamente por no practicar un trabajo manual y dedicar más tiempo al rezo. ¿Dos modos, acaso enfrentados, de concebir el espíritu y la piedad, el camino sufí de liberación terrena y acercamiento a lo divino? ¿Son los bayfal los más místicos o los más heterodoxos, cuya heterodoxia roza para algunos la herejía, en la excesiva dejación del rezo o el consumo de sustancias prohibídas? ¿Son los "locos", donde la locura interior anida ligada a la sumisión ${ }^{7}$ y a la exacerbación de la experiencia mística, al tiempo que a la renuncia de la ortodoxia ${ }^{8}$ ? $\bigcirc$ podemos ver en los bayfal el epítome de la tradición espiritual sufí? ¿Encarnan la mixtura de misticismo y marginalidad estigmatizadora de la que se habla desde la academia, pues, y cómo?

Los interrogantes recién formulados son los que conducen a la afirmación de la "antinomia vertebral del bayfalismo" o, al menos, a considerarla como hipótesis epistemológica básica de análisis: una antinomia es una contradicción entre dos principios racionales (o dos preceptos legales); veremos que "todos" los bayfal, sean cuales sean sus conductas, se autoconsideran "buenos", de modo que la afirmación o no de una heterodoxia religiosa queda reducida a la percepción identitaria y su contestación en la facticidad de la alteridad (se abundará en ello en los resultados).

El principal objetivo de este artículo es estudiar el movimiento bayfal (bayfalismo) en el seno del muridismo, desde una perspectiva transnacional y como adscripción específicamente migratoria en la contemporaneidad. Se comparará el bayfalismo original como heterodoxia sufí en Senegal, dentro de la cofradía Muridiyya, con el caso de estudio en la diáspora ${ }^{9}$ migratoria en Madrid (España) y secundaria y complemen-

${ }^{7}$ La sumisión al marabout traspasa los límites de la mera obediencia. En las condiciones para ser miembro de las cofradías, una de ellas es el amor incesante al sheik hasta su muerte, así como a su sucesor y sus escogidos cercanos (Brenner 2005: 195) (Cruise O'Brien 1969, 1970). Abundaremos en ello en el epígrafe sobre la relación entre sufismo y bayfalismo.

${ }^{8}$ En torno al uso mismo de los términos "heterodoxia" y "ortodoxia" a lo largo de este artículo, se realiza un uso instrumental de los mismos, no esencial; es decir, no consideramos en modo alguno que una interpretación más "recta" (en sus propios términos), más islámica si se quiere, del ser bayfal, que llamamos para entendernos "ortodoxa", sea mejor o peor, más o menos moral, más o menos pura, que la que llamamos "heterodoxa". Manejamos tales etiquetas porque de algún modo aprehensible hemos de referir tales realidades, pero como analista asumo, como resultará evidente, con las asociaciones de pureza o impureza, de autenticidad o no, que habita en el uso de tales significados de sus propios actores sociales.

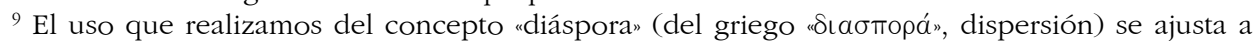
su segunda acepción del DRAE, generalizada además tanto en su empleo cotidiano como académico: "Dispersión de grupos humanos que abandonan su lugar de origen". 
tariamente Granada (Andalucía, España). Se trabaja la hipótesis de que la diáspora está cambiando tanto la forma de adscripción al bayfalismo (intensificando las adhesiones, de hecho), como los contenidos identitarios en sí de esta categoría. Asimismo, se analizará cómo los elementos típicamente sufíes en el bayfalismo resultan más visibles o prevalentes frente a su condición islámica.

Las principales conclusiones apuntan, precisamente, a esa "disputa" de y en la migración senegalesa murid que supone la compleja diáspora bayfal: cómo el movimiento se muestra como una adscripción crecientemente migratoria; cómo se está observando modificaciones en la práctica y la autoconsideración de este grupo, trasladándose la discusión sobre qué es un bayfal y, especialmente, qué son los "buenos" o "malos" bayfal, clásica en las zonas urbanas de Senegal hoy, al contexto de migración; y, finalmente, cómo algunos elementos cruciales de estas modificaciones enfatizan los elementos exclusivamente sufíes en la identidad bayfal en la diáspora, frente a elementos más puramente islámicos.

El artículo se divide en dos partes fundamentales, a saber:

- Una primera parte (epígrafe 3 y subepígrafes) de revisión y estado de la cuestión (breve recapitulación de los estudios más relevantes hasta la fecha), con énfasis en las definiciones de bayfalismo y el origen del movimiento (por la relevancia que éste tiene en la configuración de la identidad de este grupo intramurid), así como en los elementos especialmente sufíes de esta rama dentro de la Muridiyya.

- Una segunda parte (epígrafe 4 y subepígrafes) de exposición y discusión de resultados, donde se presentará los principales hallazgos en el campo sobre el bayfalismo en los casos abordados, su creciente adscripción diaspórica, la complejización de la discusión clásica sobre el "buen" y el "mal" bayfal a raíz de aquélla, los elementos de raíz sufí en la práctica comportamental y algunas observaciones con perspectiva de género.

\section{ASPECTOS CONCEPTUALES, METODOLÓGICOS Y DE TRANSCRIPCIÓN}

Como perspectiva epistemológica clave, asumimos el enfoque del transnacionalismo migratorio $^{10}$ (Suárez Navaz 2008) y, en consecuencia con él, se adopta en la metodología su versión aplicada en los multisited studies o estudios multisituados (Hannerz 199611; Ferrándiz Martín 2011: 204). Dicho de otro modo, en tanto que cualquier estudio sobre la cofradía murid y su sección bayfal ha de ser abordada desde el transnacionalismo (Kane 2011), asimismo parece óptimo considerar en su estudio distintos lugares de estudio, por así decir, en diferentes regiones españolas, en este caso. Por

\footnotetext{
${ }^{10}$ Supone una mirada que permite comprender el hecho migratorio sin las estrecheces del esquema nacional, de origen occidental por ende; estrecheces epistemológicas, pragmáticas, políticas. Enfatiza el carácter diaspórico de los grupos humanos mucho más allá de los márgenes de los Estados nacionales (bien recientes en la historia de la Humanidad, por cierto); rebasando el nacionalismo metodológico, apunta de modo crucial a esta revolución epistemológica, y epistémica, en torno a la migración.

${ }^{11}$ De ahí, como veremos en la muestra, la pertinencia de triangular datos informativos en enclaves distintos como Madrid, Alicante o Granada.
} 
otro lado, la presencia senegalesa tanto en Madrid como concretamente en Granada es notable (en comparación con otras provincias españolas, autores como Jabardo Velasco - 2006 - señalan este dato).

En función de lo anterior, el presente artículo se asienta empíricamente en el trabajo de campo etnográfico desarrollado desde enero de 2011 hasta abril de 2013 principalmente en Madrid y, de forma menor, en Granada. En la investigación se trata con una muestra intencional de población diversificada en función de la nacionalidad (senegalesa), la pertenencia a la cofradía murid (bayfal/no bayfal), el género (mujeres/ hombres) y la edad (franjas 20-30 años/ 30-50 años aprox.). De forma más concreta, se realizó etnografía (observación participante y entrevistas abiertas) entre enero y junio de 2011 en la zona de Lavapiés ${ }^{12}$ (Madrid), por constituir uno de los lugares de mayor concentración y visibilidad de migración senegalesa murid-bayfal, así como la Casa de Serigne Touba a las afueras de Madrid. El mes de junio de 2011 se dedicó a una estancia de documentación bibliográfica en el Nordiska Afrika Institutet en Uppsala (Suecia); entre julio y agosto de 2011 se completó una fase de exploración complementaria con observación participante en Alicante, estableciéndose contacto con la coordinadora de la Federación de Asociaciones de Migración Senegalesa, y por ser esta localidad levantina un lugar de especial concentración de redes migratorias senegalesas (algunos de mis contactos en Madrid habían estado en Alicante por temporadas); entre septiembre de 2011 y mayo de 2012 se realizó etnografía a través de observación participante (enclaves concretos clave en Lavapiés: restaurantes senegaleses, comercios senegaleses, plazas y diversos espacios colectivos del barrio; domicilios particulares; Casa de Serigne Touba a las afueras de Madrid) y una veintena de entrevistas abiertas y semiestructuradas en función la muestra intencional mencionada, además de la selección intencional de ciertos cargos concretos, como el de tesorera de dahira, representante en asamblea vecinal o esposas españolas en parejas mixtas; finalmente, entre mayo de 2012 y junio de 2013, se realizó observación participante en la ciudad de Granada, con visitas y entrevistas ${ }^{13}$ a una decena de informantes clave de las comunidades bayfal y un énfasis especial en las yayfal — mujeres bayfal— de origen español casadas o emparejadas con bayfal.

En la ciudad de Granada, de modo análogo a la concentración de senegaleses bayfal en la zona de Lavapiés, el lugar más frecuentado para los encuentros rituales de la comunidad bayfal es el enclave de las cuevas de San Miguel alto, pertenecientes al

${ }^{12}$ En realidad, la zona no posee personalidad administrativa como tal sino que forma parte del barrio Embajadores, en el distrito Centro de la ciudad, como ha precisado Mayte Gómez (2006) en su aguda monografía sobre Lavapiés. El topónimo "Lavapiés" lo ostentan, con propiedad, una calle, una plaza y una parada de metro. Sin embargo: "[Lavapiés] es un lugar mítico, una manera de vivir, un estilo, una historia y una leyenda. Aunque la zona no existe oficialmente como barrio, tiene una personalidad inconfundible construida y aceptada por el imaginario colectivo de toda una ciudad y, posiblemente, de todo un país" (Gómez 2006).

13 En todo momento se respeta el anonimato de las fuentes, especialmente por tratarse en muchos casos de personas en situación de irregularidad jurídica. En cuanto a las entrevistas, para las que se ha usado guiones abiertos y flexibles, no siempre se han podido grabar por las circunstancias mismas de la convivencia con las comunidades. El abordaje debía ser cercano y casi siempre informal por las propias características de los eventos y momentos, perdiéndose gran cantidad de posible información si se trataba de formalizar o restringir en mayor medida el modo de comunicación. 
distrito de Albayzín, donde existe una importante tradición de ocupación y conviven de un interesante modo análogo a como sucede en Lavapiés (siguiendo la clasificación de Gómez - 2006 — ), vecinos "de toda la vida" — especialmente de etnia gitana, la tradicional habitante de las cuevas en los barrios de Albayzín y Sacromonte-, "nuevos vecinos" en forma de estudiantes y turistas internacionales (en general, bohemia de distinta índole) y, para el caso que nos ocupa, los "novísimos vecinos" (ibíd.) en la forma de los migrantes senegaleses bayfal. De todo ello se abundará más adelante.

Se ha de precisar que no se trata de comparar dos estudios de caso autónomos, entre Madrid y Granada; antes bien, el estudio principal (tanto en tiempo como en intensidad) se llevó a cabo en Madrid, constituyendo el seguimiento de la investigación en Granada (del mismo modo que se realizó parte del estudio en Alicante, a raíz de trabar contacto con interlocutores relacionados con las redes madrileñas) un modo de complementar, enriquecer, complejizar y "triangular" los datos, debido a dos motivos fundamentales: por las características de Lavapiés (Madrid) y el enclave de San Miguel (Granada), la posibilidad de comparación es amplia y rica; por las características de las redes migratorias de los murid en general, resulta de gran interés contrastar las trayectorias de los interlocutores en lugares vinculados, siguiendo el criterio de los estudios multisituados.

Finalmente, antes de continuar, deseo realizar una precisión o aclaración sobre la transcripción de la voz "bayfal" y su grafía. La he hallado escrita de múltiples modos, los más frecuentes Baay Faal, Baye Fall, Baye-fall, Baay-Fall, Baay-faal o todo ello en sus versiones en minúscula: baye fall, etc.; es decir, oscilando entre mayúsculas y minúsculas, entre la aparición de las dos palabras por separado o bien unidas por un guión, y el "Faal" o el "Fall", que es directamente el apellido del fundador. Según Pezeril (2008), "Baye Fall" responde a la ortografía francesa, frente a la transcripción de tipo más autóctono "Baay Faal". Todo ello puede aplicarse de modo exacto a las mujeres bayfal, las Yaye Fall, o Yaay Faal, etc.

Por mi parte, y ante tal multiplicidad de transcripciones aceptables y frecuentes en los textos científicos, he optado por una transcripción netamente hispana (del mismo modo que la hay de la ortografía francesa, al decir de Pezeril) que sigue el estricto criterio de la economía lingüística y la fidelidad en la pronunciación oral; se propone, en aras de ello, la transcripción "bayfal", que respeta la "y" griega (por sonar del mismo modo que la latina) y, por lo demás, define de modo simple cómo exactamente suena la expresión en lenguaje hablado. Por los mismos criterios se usa la expresión "bayfalismo" y, en el caso del nombre específico de las mujeres, "yayfal". "Yayfal" es el término femenino para "bayfal"; si "Baye Fall" es "padre Fall", "Yaye Falle" es "madre Fall". Cuando nos refiramos conjuntamente a hombres bayfal y mujeres yayfal, usaremos el genérico "bayfal", como ellos y ellas mismas realizan; a veces también se usa la expresión "mujeres bayfal" (las mujeres bayfal se llaman yayfal", según mis interlocutores; para toda cita literal o verbatim de este tipo, se mantendrá siempre el anonimato, siguiendo la ética etnográfica clásica, e indicándose solamente la fecha para el caso de entrevistas más formales).

Todo ello puede ser, naturalmente, revisado, pero dadas las amplias varianzas halladas en el término, así como el origen oral que sustenta y anida en todas sus transcripciones del wolof original, me parece introducir de este modo un elemento de confort para el analista de habla hispana, legitimado además porque las voces murid a 
menudo siguen precisamente este criterio: el de la fiel transcripción de la oralidad ("murid", por ejemplo, lo hallamos escrito también "Mouride"; Tuba ${ }^{14}$ es también "Touba"; existe, en fin, una variedad posible y admisible de transcripciones, y aquí se optará siempre por las más económicas en lo lingüístico) $)^{15}$.

\section{REVISION Y ESTADO DE LA CUESTION}

\section{1. ¿QUÉ ES UN BAYFAL? ACOMETIDA DE UNA DEFINICIÓN}

¿Qué es un bayfal? ¿Cuál es el estado de la cuestión en la literatura académica sobre los bayfal, en términos de definición y antes de abundar en sus raíces o su presente? Dicho de otro modo, ¿qué nos topamos primeramente cuando buscamos la voz "bayfal" (en sus diversas grafías)? En cuanto a la literatura revisada, probablemente la obra contemporánea, relativamente reciente además, más completa y exhaustiva sobre los bayfal sea la de Pezeril (2008), aunque ciertamente la autora francesa se centra, sobre todo, en el bayfalismo dentro de Senegal, igual que la obra de Audrain (2002 y 2004). Veamos en una lista una compilación breve y concisa de las definiciones y caracterizaciones más notables halladas en la bibliografía revisada, y que oscilan entre descripciones operativas genéricas y atribuciones más concretas:

- Rama de la orden murid que enfatiza el trabajo sobre el rezo (Diouf y Rendall 2000: 687).

- Poseer un rol social: ser un soldado y un guardián del muridismo; ser un gor Yalla, un hombre de dios (Pezeril 2008: 302), con una doble función de estigma y de vanguardia.

- Jefes o comandantes de sí mismo (Tout Baay-fall est le commandant chez lui; Audrain 2002: 71ss).

- Apóstoles del trabajo duro (Roberts, Nooter y Armenian 2003).

- Rama sufí pacifista y tolerante (Pezeril 2008).

- Movimiento popular e inculto de neófitos del Islam, cuyo comportamiento desviado y licencioso es esperable precisamente a causa de lo primero (a saber, la popularidad y la incultura) (Mbacké 2005: 66).

- Secta fundamentalista en el seno de la orden musulmana murid en Senegal (Bocci 2010: 2).

- Opción individual en la práctica murid (Audrain 2012).

- Hombres libres que no son esclavos de nada ni de nadie (Savishinsky 1994: 215).

${ }^{14}$ Touba, hoy la segunda ciudad senegalesa después de Dakar, fue construida en el lugar de nacimiento de Ahmadou Bamba. Se ha erigido como ciudad santa de la cofradía, capital del muridismo (Guèye 2008) y lugar de obligado peregrinaje, incluso frente a Meca.

${ }^{15}$ En cuanto a las minúsculas, se opta por ellas siguiendo el criterio gramatical del español castellano, que no usa mayúsculas para nombres genéricos del tipo "musulmanes", "cristianos", etc., frente al inglés por ejemplo. Los plurales para palabras no castellanas, como "murid" o "taalibe", no se forman con la "ese" final. Por último, dada la gran cantidad de términos foráneos presentes en este artículo, no se usarán comillas ni cursiva, por lo general, cuando aparezcan, para no incomodar excesivamente la lectura. 
- Rastas musulmanes o a la africana (I am a Baye-faal, that's a Rasta in an African way" (Savishinsky 1994: 217): "The Baye Faal are an eccentric, flamboyant and beterodox Senegambian-based Islamic sect whose members' appearance and behaviour so closely resemble those of Rastafarians that some even refer to themselves as such and claim that they are in fact the "true" and "original" Rastafari" (ibid.).

Hallamos, así, ponderados elementos tan contradictorios en algunos casos como el trabajo físico, la autodeterminación, la autonomía, la excentricidad, la heterodoxia, la acometividad, la licencia, la tolerancia, el pacifismo, la incultura y ciertos rasgos característicos de índole tanto estética como actitudinal y de praxis, como el consumo de psicoactivos ilegales o el extremo misticismo interior. La cuestión del misticismo, por ejemplo, es interesante ya que pareciera opuesta diametralmente al énfasis del trabajo sobre el rezo que también se señala de los bayfal, lo que, una vez más, remarca su condición paradójica o contradictoria. En resumen, los elementos de la contradicción y la pluralidad hermenéutica son las claves presentes y constantes en todas las investigaciones realizadas sobre los bayfal hasta el presente. Nociones como desviación, marginación e incluso oprobio (Audrain 2004) se asocian a los bayfal, tanto como la revitalización y la resignificación del bayfalismo en la juventud (Aaardal 2010) (o incluso bayfalización de la juventud en contextos urbanos en Senegal; también en la diáspora, añadiremos), o misticismo o camino verdadero en la vivencia de la fe.

Por otro lado, lo que los bayfal presentan a menudo como una «ideología específica" propia, se origina en lo que llama Assan Sylla (1994) la filosofía moral de los wolof, en común con las ideas generales murid y probablemente con la filosofía de otros senegaleses también. Es una manera de pensar y vivir la religión y su moral que debe describirse con más elasticidad y dinámica, tomando los casos empíricos como punto de partida del análisis. Como estudio reciente de gran interés, Cerrolaza Molina (2014) ha profundizado específicamente en la ética murid y realizado un análisis pormenorizado de la tariqa madrileña.

\subsection{BREVE HISTORIA EXEGÉTICA DEL BAYFALISMO: DESDE EL ORIGEN, ¿BUENOS Y MALOS BAYFAL?}

Many Senegalese and foreign scholars, who have written on the Mourides, have failed to clearly distinguish between the majority of Mourides, who observe all the precepts of Islam and apply the teachings or the shaykh to the best of their ability, and this faction among them which is concerned only with its internal order and in which various dangerous elements have found a safe haven [...]. All Mourides are, then, condemned for laxity because of the Baay Fall (Mbacké 2005: 66) [el énfasis es mío].

La referencia a "buenos" y "malos" bayfal, en congruencia con el dualismo interpretativo omnipresente, jugándose con los términos en francés, los "baye fall" y los "baye faux", se refleja tanto en la literatura especializada como "a pie de calle". Esta sanción popular sobre el hecho de que existan los "bayfal de verdad" y los "malos o falsos bayfal" se enraíza, a mi entender, en los propios orígenes del movimiento, ligados intrínsecamente a una crítica desde la ortodoxia, y acaso, precisamente, porque se quiso erigir el bayfalismo como "otro modo" legítimo de ortodoxia. 
La historia de la fundación del movimiento es la historia de una devoción personal, por así decir, que se institucionalizó y "creó escuela". Sheik Ibraim Fall fue un seguidor temprano de Serigne Touba, a quien conoció en 1883. Según cuentan las crónicas (Minan al-Baqi al-Qadim, en Mbacké 2005), Fall se hallaba en plena búsqueda espiritual de un guía que le condujera a Dios. Cuando conoció a Touba en el pueblo de Mcacké-Kayor, pronto la simple y habitual sumisión del discípulo se tornó en veneración dramática por el maestro (que fue el primer sorprendido, cuentan); siguiendo con la tradición (sufí en general y murid en particular) de las leyendas que siempre se recuerdan, se comenta cómo Fall bebía el agua de las abluciones de Serigne Touba, por ejemplo. Acaso por sucesos así muchos son los que piensan que Ibra Fall es el responsable de introducir en el movimiento "desviaciones" (vistas al principio como tal, poco a poco y más tarde legitimadas en cierto modo) tales como la sumisión total, la veneración excesiva o el trabajo incansable por el solo beneficio del sheikh (Mbacké 2005). Veremos, sin embargo, que es también propia del sufismo la vinculación especialmente estrecha con un líder espiritual, lo que dificulta la delimitación de lo que sea una veneración "excesiva" frente a otra preceptiva y aceptable en el sufismo.

¿Pero quién fue Ibraima Fall, el que llegó a considerarse el modelo de murid perfecto (de nuevo, incurriendo hoy en una paradoja según las propias percepciones recogidas)? Nos topamos con linajes reales, ya que era un miembro de la familia real de Kayor, concretamente del linaje de los tyeddo, la guardia real (su abuelo abandonó la profesión para convertirse al islam), y que, a través de diversas empresas comerciales, había amasado una fortuna considerable (fortuna que, por cierto, puso a los pies de su sheik) (Iniesta 2009).

Ibra Fall pronto generó a su vez una intensa devoción especialmente en los miembros de su familia extensa, una devoción a menudo considerada tan excesiva como la propia de Fall con Serigne Touba (en palabras de mis interlocutores, "Su sombra"). Ibra Fall es también definido (Iniesta 2009: 12ss) como un jefe militar animista en los reinos wolof que se enfrentaron a Francia; un converso sincero, enérgico y reconvertido al comercio tras la guerra; guardia personal de Serigne Touba, a quien defendía "Solo con la fuerza física y ocasionales bastonazos" (ibíd.). Los bayfal fueron antes "bulliciosos y ebrios soldados paganos" (ibíd.) y, desde la conversión de Ibra Fall, "fieles musulmanes con ciertas dispensas en la ingesta de alcohol o en la danza con sus espectaculares tambores largos bajo las axilas" (ibid.: 29-30).

Pronto el "bayfalismo", la corriente de seguidores de Fall, se extendió y fructificó, hasta el punto de que los llamados Baay Fall o bayfal, seguidores de Ibra Fall, se constituyen como su coro social y económico (eran muy productivos en el cultivo del cacahuete, por ejemplo). Desde el principio se reveló igualmente crucial su concurso para la construcción de edificios y emplazamientos, desde mezquitas hasta carreteras, como fuerza de trabajo útil y eficaz (Mbacké 2005: 65), lo que ha sido proverbial hasta la actualidad. Desde el inicio, en fin, se ha remarcado como su rasgo distintivo por antonomasia su peculiar comportamiento, el mismo que les ha dado fama, singularidad y representatividad sociales, incluso estéticas (Aardal 2010: 65ss), en las calles fuera y dentro de Senegal.

Los estudios contemporáneos sobre bayfalismo privilegian las siguientes consideraciones cruciales, a la luz de cómo ha devenido y evolucionado el movimiento, todas ellas a su vez muy intensamente ligadas a la dimensión diaspórica: el ámbito ur- 
bano, el factor de la migración y los crecientes vectores de la juventud y la feminización. En virtud de ello, Pezeril (2008) complejiza, pluraliza y en definitiva enriquece las primeras hermenéuticas sobre el movimiento; en sus palabras, se ha diversificado, globalizado y feminizado y, muy especialmente, a través de una dinámica de individualización que ella reconoce en la sociedad senegalesa, ha evolucionado hacia la reivindicación de mayores libertades por parte de los discípulos (Pezeril 2008: 299).

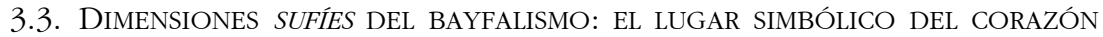

¡Con todo tu corazón, con toda tu alma, busca este conocimiento de ti mismo! (Skali 2006: 31).

El sufismo consiste, por tanto, en un camino cuya única meta es el conocimiento de Dios que se recibe mediante la experiencia espiritual y que compromete al ser humano en su totalidad, hasta lo más profundo de sí mismo; profundidad entonces designada con el término simbólico de "Corazón" (Skali 2006: 31).

En mis convivencias con los diversos bayfal he encontrado de forma recurrente un gesto singular: llevarse la mano al corazón y apelar a "razones" para la fe y la vivencia bayfal inexplicables desde perspectivas, gramáticas o narrativas racionalistas, incluso meramente lingüísticas: "hay que sentirlo, sentirlo aquí, en el corazón" (según testimonios varios de personas interlocutoras en el trabajo de campo). Ello supone una referencia ineludible a la experiencia de re-ligamiento espiritual sufí: la centralidad de la experiencia del creyente (corporalizada en el centro sutil del ser, a saber, el corazón), el imperativo del corazón y, finalmente, los factores del control oculto y el secreto (Pezeril 2010: 449). Dicho de otro modo, encontramos un énfasis en la vía esotérica del sufismo (frente a la exotérica, que supondría el establishment murid no bayfal, más seguidor de la sharia), por un lado; y, por otro lado, un repunte especial en la relación maestro-discípulo, al tiempo que un reconocimiento de autonomía y autogestión espiritual (frente a la vía exotérica, nuevamente). Todo ello supone igualmente rasgos sufíes de modo notorio, aunque no negamos, por otro lado, que el sufismo bayfal se desmarque también de un sufismo ortodoxo, como han visto Samson (2009) o MBacké (2005) ${ }^{16}$.

El islam se comprende en un aspecto exterior consistente en una ley revelada (sharia) y un aspecto interior que, a través de un camino espiritual (tariqa, camino místico, método) (Skali 2006: 35), ha de conducir al conocimiento de la verdad primordial, la haqiqa (Skali 1993). Tales caminos, exotérico y esotérico, no son excluyentes sino complementarios según la comprensión clásica del sufismo: "las dos alas de un mismo pájaro" (ibíd:: 33). Sin embargo, el camino espiritual, el esotérico, hay que "sentirlo": no consiste solamente en la aplicación de la ley sino que es ante todo una experiencia "vivida, sentida e inefable", que se "saborea" (ibid.: 36) ${ }^{17}$.

\footnotetext{
${ }^{16}$ Cfr. Piga (2003).

17 Resulta curioso que a menudo se establezca, en la literatura sufí, una analogía de tal experiencia precisamente con la embriaguez y el vino: “Cómo puede uno enseñar lo que es la embriaguez a aquel que nunca ha bebido vino"? (ibid.); ello es, por ejemplo, ampliamente evocada por el poeta sufí egipcio Ibn-al-Farid en L'Eloge du vin (Skali 2006: 36).
} 
El mismo sufismo en sí es definido como un "Conocimiento del corazón" (Skali 2006: 32): "El corazón del Hombre perfecto (insan al-kamil) es la fuente original de los corazones y su mediación es pues indispensable para alcanzar la unión mística, wissal, es la "puerta" (bab) por la cual para el camino para llegar a Dios"; "Aquí está, te he traído un corazón!, Dios te dirá: ¡Trae el Corazón que es el Polo (qutb) del mundo y el alma de Adán!» (Rumi, Mathnawi, V, 870.). Y el corazón mismo, qalb, es definido como el órgano espiritual que permite el conocimiento de la verdad (ibíd: 34) (es interesante reparar, por cierto, en que en otras tradiciones espirituales, como la yóguica vedanta, el centro espiritual del ser, o chakra central y del corazón, se considera ubicado en el mismo lugar corporal).

Todo ello representa elementos clave del sufismo. Como precisa Mbow (2000), hoy en día los bayfal se reconocen en una valorización del sufismo y, especialmente, la "haqiqa", la vía esotérica por cuya opción se distinguen del resto de murid, observantes más fieles de la sharia. "Haqiqa” es el camino interior, el del corazón, el cuerpo y el alma, que envuelve totalmente al discípulo en su búsqueda de la divinidad. El bayfalismo actual, además, trata de explicar y difundir dicha particularidad a través de la organización de conferencias, publicaciones y sitios web diversos (ibíd.).

En el sufismo hay una clara distinción entre lo exterior, zahir, y lo interior, batin (Skali 1993: 36). En palabras de Audrain (2004: 10-13), dicha distinción (entre njëbëlu zabir y njëbëlu bâtin) condensa una intensa carga afectiva: "Dans la philosophie soufie, le njëbëlu relève bien d'un désir et d'une décision personnelle, provenant du for intérieur, fruit d'une longue maturation. Alyoune a décidé ce qu'il voulait vraiment être au prix de sa séparation d'avec sa famille» (ibid.: 13). Aquí volvemos a encontrar reseñado el aspecto del camino interior - bayfalismo en nuestro caso- como decisión personal que puede incluso, en ocasiones, suponer una separación o enfrentamiento con la familia de origen.

\section{DIÁSPORA BAYFAL EN ESPAÑA}

4.1. A MODO DE PREVIO: EL "BUEN" Y EL "MAL" BAYFAL, ¿UNA PARADOJA MORAL IRREDUCTIBLE?

We make our own rules, and we are accountable only to God and his prophets. Some Baay Faal smoke, some don't, some pray, some don't (Moussa Ngom, en Savishinsky 1994: 215).

Nosotros no nos paramos a rezar cinco veces al día porque estamos todo el día rezando en nuestro corazón, por dentro (interlocutor Murid, migrante en Madrid, entrevista 12/ 12/2011).

Mi primera aproximación a los bayfa ${ }^{18}$, como acaso sea lo más deseable, fue absolutamente empírica y "virgen de teoría" ${ }^{19}$, por así decir. Yo no había leído nada so-

\footnotetext{
${ }^{18}$ Puede consultarse un avance preliminar y resumido de esta investigación en Massó (2014).

19 Se considera apropiado incluir esta breve autorreflexión etnográfica o apreciación personal ya que todo ello es básico en un trabajo de campo antropológico; lo que se pretende es mostrar, en fin, el aspecto crucial de cualquier etnografía: la impresión de la observadora en función de su propia situación, nada menos que el conocimiento "situado", crucialmente singular en este caso por la complejidad que anida en las condiciones de ser senegalés-murid-bayfal/no bayfal.
} 
bre el movimiento y carecía de toda formación o contaminación informativa al respecto cuando comencé mi trabajo de campo interesada en el muridismo migrante en España. Antes de saber intelectualmente qué es un bayfal, conocí a uno en un restaurante senegalés de Lavapiés, que amablemente me convidó a asistir al Gran Magal celebrado en enero de 2011 en Madrid (a la par que en Touba, naturalmente, y orquestado de hecho desde allí) donde encontré a multitud de bayfal y yayfal en plena acción mística y física, por así decir, sin saber yo lo que eran, pero "experimentando" lo que hacían. Así, el primer bayfal que conocí no llevaba rastas y procuraba ser un estricto practicante de los cinco rezos, así como del trabajo físico o de la fidelidad al marabout; tampoco consume ningún tipo de sustancias psicoactivas (salvo café Touba) y denuncia que se haga, ante quien quiera escucharlo.

A la par que a ellos, rápidamente tuve acceso en las calles de Lavapiés a otros bayfal con rastas y ropas coloridas que consumían cannabis e incluso alcohol con asiduidad. Mi experiencia fue desde el inicio la visión empírica y espontánea de la pluralidad en el bayfalismo. He encontrado tanto bayfal ebrios, expeliendo claro aroma a alcohol, quienes con la mano en el corazón, en el gesto clásicamente sufí, me hablaban de su experiencia mística de la divinidad, cuanto bayfal que denunciaban tales conductas, aduciendo que la dejación se debía precisamente a la distancia de la diáspora (por ejemplo, a que no estén los padres cerca para verlos y que se sienta que puede avergonzárseles ante la comunidad, entre otras posibilidades); yayfal que criticaban la inactividad de ciertos bayfal ya que, frente a ésta, los bayfal (o yayfal) deben mostrar una entrega apasionada e incansable al trabajo y al servicio ("eso no son bayfal, eso no es ser bayfal... ser bayfal es que, si ves que se me va a caer algo al suelo, lo coges al vuelo antes de que toque el suelo... que estés siempre pendiente de lo que haya que hacer"; interlocutora yayfal, migrante en Madrid, entrevista 25/03/2012).

Y, por supuesto, he encontrado Murid no bayfal que llegan a definir a los bayfal como "punkies" (sic) indeseables; o bien, "falsos" bayfal, cuasi herejes, "gente equivocada", acaso aprovechando la laxitud que permite la sociedad acogedora en la migración. Así, podemos hablar de dos grandes contradicciones o pugnas halladas en el campo de un primer modo intuitivo:

- Pugna "interna" y específica en el bayfalismo: bayfal "auténtico" / bayfal "inauténtico".

- Pugna en el muridismo, entre la corriente mayoritaria no bayfal y la sección bayfal: murid no bayfal como "auténtico / murid bayfal como «inauténtico".

Maravillada por tales contradicciones, por tantas pasiones encontradas, por tantas pugnas más o menos veladas, tantas críticas más o menos encendidas y tal riqueza interpretativa, y solo entonces, comencé a leer sobre la cuestión, aún más estimulada por la ausencia manifiesta de abordajes específicos sobre bayfalismo en los diversos estudios sobre migrantes senegaleses en España.

Finalmente, parece que la paradoja esencial puede resumirse en la distancia que se abre (y su contenido) entre ser un "buen" o un "mal" bayfal, que a su vez se complementa a la oposición entre ser un "buen" o un "mal" murid, y por supuesto la "autoconsideración" de cada cual, ya que ningún bayfal se autoproclama como "falso", lógicamente, con lo cual nos topamos con el más que viejo problema del "poder": quién "manda" en las interpretaciones, quién sienta la ortodoxia sobre qué es ser buen o un mal bayfal. 
El trabajo de Pezeril (2008) aborda precisamente esta paradoja y acaba por realizar un cuadro que la trata de explicar, ofreciendo una dicotomía, que sin embargo continúa sin resolver el problema del poder o la hegemonía interpretativa, sobre lo que sea un "verdadero" bayfal y un "falso" bayfal, en los términos siguientes:

a) bayfal "verdadero": [palabras clave] inclusión, servicio, comunidad, trabajo, normatividad/austeridad, ámbito rural, dificultad.

b) bayfal "falso": [palabras clave] exclusión, liberalidad, individualismo, inactividad, transgresión/droga, urbano, facilidad.

Es importante insistir en que la discusión sobre ser un buen o un mal bayfal, ya sea dentro o fuera de Senegal, no solo aparece en la literatura, sino que se trata de una alusión frecuente en los discursos de personas bayfal migradas en España, probablemente tan frecuente como esta discusión clásica sea en cualquier otra adscripción espiritual o religiosa. Ser bayfal supone una forma de vivir, un compromiso holístico, de enfrentar la vida en todas sus dimensiones; se puede "nacer" bayfal ("Tú lo has visto desde pequeña en tu familia, en tus abuelos, vivirlo a tus padres... y tú también quieres vivir esa devoción", según una interlocutora yayfal) pero, muy especialmente, se puede "devenir", tender hacia ello, a través de mucho trabajo espiritual y físico (los constantes amal y kasbu), y esta elección implica una dimensión existencial que ocupa muchas facetas de la vida ( Ser bayfal ... puede ser independiente, no viene de familia. Es dependiendo de lo que pueda sentir cada personan; ibíd.). Así, ello implica un campo de cultivo especialmente abonado para la prescripción moral y el enfrentamiento de diversas formas de enfocar cómo se debe ser/hacer para considerarse, y ser considerado, un "buen" bayfal.

En el contexto diaspórico, y teniendo en cuenta que muchos senegaleses jóvenes no bayfal se "adscriben" al movimiento tras la migración dada su fuerza de cohesión y de motivación emocional, las prescripciones sobre el ejercicio del bayfalismo adquieren un peculiar carácter. Hemos hallado una apelación a auténtica ortodoxia sobre la prohibición de beber alcohol o "saltarse rezos", sumada a una feroz crítica a los "malos bayfal" que fuman cannabis por las calles, a la par que una reclamación por parte de estos consumidores de psicotrópicos acerca de su poderosa fe en Allah, y que precisamente dicho estado de alteración de conciencia es lo que permite "sentir" de esa manera.

Por otro lado, la cuestión parece recrudecerse en su complejidad si atendemos al interesante dato de que "todos" los bayfal se autoconsideran buenos; es decir, nadie se acomoda bajo la etiqueta de mal o falso bayfal, sino que siempre es una aseveración que se predica de "otros"; dicho de otro modo, todos los tipos encontrados de bayfal consideran que son "buenos", que encarnan la forma correcta de serlo. Así, podemos hallar aquí una versión propiamente poscolonial y posmoderna, típica de la globalización, de la vieja paradoja de la alteridad, tan cara a la antropología: ¿quién designa qué es la alteridad? Uno mismo nunca es alteridad, o bien lo son todas las partes. Dicho de otro modo, la alteridad solo existe desde los ojos de una cuestionable "mismidad".

Ante esta tesitura, esta especie de camino sin salida que hallamos en el análisis del bayfalismo y la constante referencia moral a ser "buen" o "mal" bayfal (ligado a ser un buen o un mal murid), nos formulamos la pregunta que encabeza este epígra- 
fe sobre si la paradoja esencial que subyace al análisis del bayfalismo no es de tipo "moral": qué se considera bien o mal y, sobre todo, "por quién".

\subsection{DOS EJEMPLOS SIGNIFICATIVOS: PARADIGMAS DE "SER BAYFAL"}

Presento como ejemplos significativos de mi trabajo de campo a dos de los interlocutores clave en la investigación, uno representativo de la vía más estricta o fundamental, y el otro de la vía más heterodoxa.

En el caso del informante más ortodoxo, era un joven senegalés cercano a la treintena, hijo de la tercera esposa de un anciano y prolífico wolof bayfal de Touba. Divorciado de su esposa, en Senegal, con la que no tuvo hijos, llevaba cuatro años en España, sin regularización de papeles y con empleos irregulares pero más o menos constantes. Su discurso afirmaba que ser bayfal constituye la forma más perfecta, comprometida y entregada de "practicar como murid", comenzando por el ejercicio inviolable del rezo cinco veces al día, la observancia firme del ayuno en Ramadán o la negativa a consumir ni una gota de alcohol, ni, por supuesto, carne de cerdo. A menudo lo encontraba rezando en gran concentración, curu y Coran en mano, y me pedía silencio hasta que terminaba. Acudía fielmente a todos los llamados, encuentros, fiestas o peticiones que llegaran de la dahira o del marabout para mostrar respeto, entregar horas de trabajo, fregar cacharros, organizar recepciones a los líderes espirituales, limpiar locales... y, como elemento fundamental, dar a conocer la palabra sagrada de Ahmadouh Bamba, cuya obra escrita conocía al dedillo; en varias ocasiones quiso llevarme a conocer y mostrar mis respetos a su marabout, cuando llegaba de viaje, incluso con el fin de que bendijese a mis hijos, entonces bebés. Concretamente su visión y su vivencia del trabajo físico eran especialmente laboriosas y disciplinadas, pero no opuestas al cultivo espiritual, como señalábamos.

Los valores de la responsabilidad y el respeto, así como la respetabilidad social, eran cruciales en su discurso; por ejemplo, miraba con abierto rechazo a personas amigas españolas del entorno senegalés que mostraran públicamente su homosexualidad, ya que el matrimonio con fines procreadores es el objetivo principal de una unión sexual según el canon musulmán que él comprendía. Incluso miraba con rechazo que los amigos a su alrededor consumiéramos una cerveza, por ejemplo. A diario, mientras realizaba sus faenas o trabajos habituales, sobre todo en la tienda o el restaurante donde trabajaba, escuchaba como música de fondo los versos leídos y cantados de Bamba, afirmando que dicha escucha "libraba" de que la policía les parara por la calle para pedirles sus identificaciones, siguiendo un clásico pensamiento mistero-mágico y de eficacia simbólica de una creencia.

En el caso del informante representativo de la vía heterodoxa, es igualmente un joven wolof de origen senegalés, cercano a la treintena, oriundo de Saint Lois y familia de origen no bayfal; emparejado con una mujer española (no yayfal), con la que tiene un bebé; sin empleo ni situación jurídica regularizados. En su discurso y su práctica bayfal encontramos prácticas claramente denostadas por el grupo anterior, como el consumo de cannabis o alcohol en los bares de moda, sumado a la venta ilegal de estupefacientes a pequeña escala ("trapicheo" de marihuana, hashish...), la dejación del rezo cinco veces al día con el pretexto de que ellos se ocupan más de "tareas físicas", 
o el establecimiento de relaciones sexuales fuera del matrimonio con chicas españolas "no creyentes" y/o más "liberales" (no nos referimos a los que se casan, formando familias según el esquema tradicional senegalés, con o sin co-esposas, según la clásica poliginia). Asimismo, encontramos la proliferación de pautas de ocio ligadas a lo anterior, como bailar y consumir alcohol durante toda la noche en ciertos locales; incluso comportamientos tildados por el ala más estricta como "de pereza", como la inactividad o el levantarse tarde, frente a la extrema vocación de servicio que un "verdadero bayfal" debe mostrar.

Los bayfal más estrictos afirman que eso se debe a que están lejos de las familias y relajan moralmente su comportamiento, que lo hacen "porque allí sus padres y madres no les ven". Sin embargo, el discurso de este informante (y otros análogos) acerca de su propio bayfalismo se orientaba principalmente a aspectos emocionales, espirituales y místicos de su forma de sentir a la divinidad: cerraban los ojos, se tocaban el corazón, recitaban algunos versos de Bamba, y afirmaban que solo "sintiendo", y no expresando palabras racionales, se podría comprender lo que ellos vivían. A menudo también solían formar los corrillos o agrupaciones que recorren las calles de Lavapiés en Madrid, a ciertas horas del día, cantando salmodias típicamente bayfal y tocando tambores, pidiendo pequeñas limosnas que ofrecer a la comunidad especialmente en los magales. Muchos de estos recorridos eran realizados tras haber consumido alcohol o cannabis, aunque no siempre. Este comportamiento es completamente análogo a la conducta de los bayfal en Senegal, donde es frecuente encontrarlos en la entrada de las mezquitas como "mendigos" de dahiras diferentes, siendo su "trabajo" mendigar y leer oraciones para la gente que les da limosna.

Se ha de matizar, por otro lado, que nunca encontré, ni en este informante clave ni en narraciones de personas análogas a él, una declaración explícita de desobediencia al marabout, o una afirmación contundente sobre que consumir ciertas sustancias fuera bueno para la iluminación. Más bien, eran las prácticas en sí mismas, observadas durante la etnografía, las que daban cuenta de estas preferencias. Igualmente, de los bayfal más ortodoxos que rechazaban el comercio ilegal a pequeña escala de marihuana realizado por sus colegas "díscolos", regentaban ellos mismos almacenes ilegales de productos de imitación de firma para su posterior distribución y venta, lo cual no era considerado contradictorio con sus creencias, como sucedía el caso mismo del primer informante clave mencionado. Así, parece ser el elemento en sí de la sustancia psicoactiva y su consumo humano, y no la ordenación jurídica de un territorio concreto, lo que para estas personas constituía fuente o no de reprobación moral. En ambos tipos de bayfal, a fin de cuentas, encontramos que hay valores y motivaciones por encima de una ley nacional específica, aunque varíen sus argumentaciones y prioridades.

Por otro lado, algunos de los comportamientos mencionados, como el de los consumos o la dejación del rezo, también han sido profusamente descritos por los bayfal en espacios urbanos de Senegal (especialmente Dakar), de modo que podemos considerar que no es la migración, como factor en sí, la variable independiente o detonante, sino el espacio urbano en sí mismo; dicho de otro modo, sí es la migración el factor clave pero no necesariamente la migración transnacional, sino la que opere o suceda en cualquier circunstancia: intra-nacional, en Senegal del campo a la ciudad, por ejemplo, o inter-nacional, para nuestro caso de estudio; todo aquello que implique, en fin, la exposición a influencias y elementos culturales diferentes de los del origen. 


\subsection{SUfismo BAYFAL EN LA PRÁCTICA: EL CORAZÓN Y LA MÍsTiCA}

Los llamados sickaar y doukar, los cantos y las danzas a la divinidad espiritual, son los elementos centrales que unen los encuentros de misticismo bayfal. Normalmente son precedidos por charlas y encuentros previos en el espacio de "dahira" y, sobre todo, el compartir del tradicional café Touba e incluso alguna comida colectiva. Cuando el ambiente se considera preparado, alguien comienza con una "llamada", algún poema o verso dedicado a Touba, y se inicia el círculo de rezo, el «kourel» (con o sin tambores, dependiendo del día), en el que las personas que lo deseen se juntan formando un círculo que se mueve lentamente, al ritmo de los cantos salmódicos y repetitivos. En el centro del círculo suele haber algún tipo de recipiente destinado a recoger limosna. Estas celebraciones (generalmente bisemanales) se celebraban en un local específico alquilado en el barrio de Lavapiés, en Madrid, y en una cueva "okupada" en la zona San Miguel, en Granada.

Se considera que entrar en estos círculos, experimentar en el propio cuerpo el canto y el caminar conjunto, es lo que permite sentir qué se significa ser bayfal. Es curioso que, con frecuencia, en la antesala de la dahira (sobre todo, previo a la entrada de la cueva) hay un grupo de bayfal que consumen cannabis o tabaco. Ello jamás lo hacen dentro de la dahira y, además, suelen justificar que dicha práctica no es apropiada para el "espacio de pureza" que supone el del kourel. Después, tras su celebración, es también frecuente que algunas personas se unan a sus amistades "españolas" en la marcha nocturna por bares diversos, donde se consumirá alcohol, también prohibido en el espacio sagrado. Ante ello, estas personas suelen aducir que "así se purifican". durante el kourel. Sin embargo, en una comprensión antropológica (más etic, acaso), podríamos considerar que estos consumos compartidos son parte esencial de la formación de comunidad y la identidad colectivas que suponen, en un espacio urbano y de diáspora, ser bayfal.

Como se dijo en la parte primera del artículo, en esta rama murid parece encontrarse de modo más acusado el rasgo del sufismo que el rasgo del islam; dicho de otro modo, la pertenencia o el carácter sufí parece notarse más o prevalecer frente a la pertenencia o el carácter estrictamente musulmán (recordemos que la Muridiyya es una cofradía musulmana y sufí, condiciones que, como es sabido, no siempre concomitan), sobre todo si atendemos a cierta interpretación "diversa" sobre la práctica de algunos de los cinco pilares básicos del Islam, frente al mayor énfasis en otras conductas.

La razón clave para defender esto es que hallamos en los bayfal, en general, una reclamación de la interioridad y el autoconocimiento, además de la autoafirmación decisional, como caminos preferentes para la aproximación a la divinidad. En ello se otorga una crucial importancia al lugar simbólico del corazón como centro del ser o al uso de cantos extáticos para elevarlo ${ }^{20}$.

Hallamos en el bayfalismo un uso activo y recurrente de las técnicas clásicas de "enseñanza" del sufismo, como la narración de milagros (Skali 2006: 83ss) y, sobre todo,

\footnotetext{
${ }^{20}$ En torno al lugar simbólico del corazón en el sufismo hallamos nutridas referencias (Skali 2006: 30ss): "¡Con todo tu corazón, con toda tu alma, busca este conocimiento de ti mismo!" (Skali 2006: 31); "Ve a purificar los estantes de tu corazón, para que un ángel venga a morar en ti" (ibid:: 31).
} 
la concentración y la meditación en un determinado número de atributos divinos a través, por ejemplo, de la invocación (dhikr) de nombres divinos, explícitamente recomendada en el Corán. Los bayfal precisamente suelen adoptar la invocación más corriente y que resume todas las demás, a saber, la de la certificación de la unidad divina, en árabe "La ilaha ella Allah", "Ninguna divinidad, solo Dios" (Skali 2006: 30). Se alude a menudo, también, a que mientras se está trabajando se realiza una meditación consciente a través del rezo concentrado (lo que, recordemos, les exime de rezar, según muchos de ellos las cinco preceptivas oraciones diarias).

Se considera que los poemas místicos cantados en las reuniones sufíes tras las sesiones de invocación (dhirk) colectivas tienen el efecto de despertar, por sus alusiones (ishara), determinados estados espirituales (ahwal), que son la expresión exterior del amor divino y el profundo anhelo experimentado por el alma — chispa divinapor reunirse con el principio superior que emana (Skali 2006). Dicho "hal", o estado espiritual, puede manifestarse como tendencia a llorar, reír o gritar, y supone también un desahogo para manifestar el amor que se revela después de un sentimiento intenso de la presencia divina; se expresa igualmente a través de los movimientos extáticos de los sufíes (en los bayfal, los círculos), designados con los términos de hadra (presencia divina), imara (plenitud) e incluso khamriyya o embriaguez (Skali 2006: 31). Así, se constata cómo el cuerpo (a través de funciones que puede desarrollar de modo expreso como ciertos movimientos o sonidos), lejos de negarse, deviene vía para la iluminación del espíritu.

Todo ello, registrado en textos sufíes clásicos (aunque contemporáneos como el Skali, practicante él mismo ${ }^{21}$ ), es claramente constatable en el bayfalismo y ha sido registrado en el trabajo de campo; numerosos testimonios bayfal corroboran cómo a través de los encuentros para la invocación se llega a alcanzar determinados estados extáticos, en algunos casos hasta rayanos en el peligro o la autolesión, como el del observado en algunas personas que, en tales circunstancias, sufren una especie de "ataques" en los que pierden el control (por ejemplo, tratando de golpearse la cabeza contra una pared o una silla). Este fenómeno suele despertar en su interpretación y narración por parte de los interlocutores, por cierto, pareceres diversos: la explicación oficial suele ser la de una lucha interna entre el bien y el mal dentro del "afectado", que le causa tal necesidad de desahogo, o bien una exaltación "inaguantable" por exceso de mística, por así decir, lo que a su vez suele despertar una visión algo escéptica, entre displicente y crítica, entre los observadores, que han llegado a afirmar que se "finge" para dar la sensación de mayor espiritualidad ("No hace falta llegar a eso", afirman con severidad).

\subsection{LA FUERZA CENTRÍPETA DEL BAYFALISMO EN LA DIÁSPORA: «HACERSE» BAYFAL Y YAYFAL}

These Baay Faal must deal with the importance of ndigël or submission on one side, and with freedom on the other side. Generally, they perfectly assume this contradiction (Pezeril $2007^{22}$.

\footnotetext{
${ }^{21}$ Faouzi Skali es también miembro del Grupo de Sabios de la Comisión Europea para el Diálogo de Pueblos y Culturas.

${ }^{22} \operatorname{Sin}$ numeración específica.
} 
Sí, yo soy yayfal, yo me considero una yayfal aunque digan... lo que digan [...] Nosotros decimos que si no hubiera sido por Sheikh Ibra Fall, no hubiéramos conocido a Serigne Touba [...] Los bayfal trabajan como los que más, porque ellos piensan que la manera como Dios les va a recompensar es por su trabajo (interlocutora yayfal, migrante en Madrid, entrevista 30/04/2011).

Un hecho fundamental que se ha revelado a lo largo de la investigación es que el bayfalismo ha visto crecer su fuerza centrípeta o de atracción como adscripción murid en la diáspora. En mi opinión ello sucede en ámbitos urbanos porque opera funciones similares a las de tribu urbana ${ }^{23}$, especialmente en los más jóvenes, que a su vez une el camino de ciertos bayfal con el de amigos y "colegas" españoles con los que comparten prácticas típicas de diversión urbana, como pueda ser el consumo de alcohol o cannabis y acudir a ciertos bares a escuchar música y/o tratar de ligar con jóvenes "blancas", como decía más arriba. Estas conductas, tradicionalmente asociadas al "ser mal bayfal" (Muchas veces, los que se llaman bayfal, para mí no son bayfal... hacen cosas que Sheikh Ibra Fall no harían... es como si ser bayfal fuera ser un pasota y no es eso. Esa interpretación la quieren usar como excusa", afirman algunos), y que se piensa que obedecen a la "relajación" de moral propia de la migración, suelen ser fuertemente denunciadas por los bayfal más ortodoxos, como veíamos anteriormente, a menudo los que no llevan rastas o ropas de colores. No existe una correspondencia plena entre cierta estética más llamativa y consumos de psicoactivos, por ejemplo, o estética más sobria y mayor rigidez espiritual, pero sí he observado una cierta concomitancia.

Ello se liga con el modo de adquisición de la identidad bayfal, es decir, cómo y por qué se es bayfal: ¿se nace o se hace? Así, hemos hallado dos grandes grupos en esta cuestión:

- Los bayfal que "nacen", es decir, que "heredan" su condición, ya que al ser hijos de un bayfal entienden que ellos también lo son, por transmisión familiar.

- Los bayfal que "se hacen", que "devienen" bayfal a lo largo de su vida y en un momento dado, a menudo, en nuestros casos específicos, ligado a la migración como transformación: bien a la migración del campo a la ciudad (en Dakar, ámbitos urbanos estudiados por Pezeril, Audrain o Aardal) o en la diáspora transnacional, en mi caso de estudio, Lavapiés o Granada. Sucede, por así decir, una traslación de valores que requiere una adaptación cultural e identitaria, suscitando por tanto incluso la necesidad de una nueva identidad que se superpone a otras: la bayfal, que transciende una esfera meramente religiosa para ocupar todos los espacios y narrativas cotidianos: "Mis padres no son bayfal,

${ }^{23}$ Entendemos "tribu urbana" en el sentido de subcultura (a menudo juvenil) propia de los espacios urbanos contemporáneos, que puede formarse a raíz de marcadores identitarios tan variados como el género, la etnia, las preferencias estéticas o la idiosincrasia lingüística, de apariencia, etc. La rebeldía y las conductas llamadas "oposicionales" en general suelen resultar cruciales en estas bandas. Las explicaciones antropológicas sobre las bandas juveniles - localizadas a menudo en contextos de exclusión-, implican una dimensión simbólica de la vida social, "y en particular son tributarias del concepto de culturas subalternas [...] Con ellas se quiere referir a las dimensiones expresivas de la experiencia social de los jóvenes a partir de la construcción de estilos de vida distintivos, localizados básicamente en el tiempo libre o los espacios intersticiales de la vida institucional» (Padawer 2004: 1), afirma esta autora. Ver también Feixa (1998). 
yo me he hecho bayfal aquí, no hace falta que tus padres sean bayfal de antes, pueden ser o no ser, yo me hice aquí, al venir de Senegal. Descubrí este camino [...] te lo dice tu corazón", comentaba un interlocutor (bayfal, migrante en Madrid, entrevista 12/01/2012). En la voz de otra yayfal: "Es una elección que tú haces, tú ves que hay un grupo que están rezando y otro que está trabajando, pues es con el que tú te sientas más identificado" (bayfal, migrante en Madrid, entrevista 02/04/2011).

Así, encontramos distintos modos de hacerse bayfal, ligados a su vez a distintas concepciones de la ortodoxia. En función de ello, se ha observado con frecuencia que las personas que "heredan" ser bayfal procuran, en principio, una interpretación y una agencia más fieles a la ortodoxia, mientras que las que "se hacen", y especialmente en la diáspora (migración urbana), pueden ser más tendentes a hermenéuticas heterodoxas de la cuestión, en tanto que la identidad bayfal asume otras funciones, aproximándose al carácter de una tribu urbana. Todo esto, por supuesto, no pretende ser exhaustivo o marcar una asociación necesaria entre las variables, sino reflejar una parte de la realidad que se viene hallando en el campo de modo recurrente.

Otro vector en análisis interesante en la cuestión, que marca igualmente una diferencia, es el carácter de las yayfal en la diáspora: por lo general, las yayfal con las que se trató en el campo han "devenido", han adquirido tal identidad no por nacimiento sino a lo largo de su vida, y en ellas hemos solido encontrar, frente a la heterodoxia más frecuente en los varones, una insistencia en la observancia fiel de los principios rectores sobre el trabajo y la rectitud conductual. Asimismo, en las yayfal de origen no senegalés, yayfal "blancas", de origen español, halladas en gran medida tanto en Madrid como en Granada (frente a un número mucho mayor de yayfal senegalesas viviendo en Lavapiés, menor en Granada) hallamos igualmente un discurso notablemente espiritual y riguroso en su praxis de fe, por así decir, que suele complementarse en muchos casos con elementos sincréticos.

Con respecto a esta cuestión de género, en mi trabajo de campo en Madrid una de las informantes clave fue una joven yayfal, de apenas veinte años, de origen senegalés pero residente de larga duración en España (con perfecto dominio de la lengua española), soltera y con trabajo remunerado (coherente con su formación profesional), más un papel protagónico en la dahira femenina. Esta yayfal hablaba con pasión sobre la importancia del bayfalismo dentro pero especialmente fuera de Senegal, porque da "sentido" y "alegría" a las personas lejos de su tierra y de los suyos. Expresaba cómo ser yayfal es, para ella, el camino más propio de ser Murid, no para ser eximida de rezar o de otros deberes y tradiciones sino, precisamente, para practicar con mayor ahínco en amor por Ahmadou Bamba y, sobre todo, seguir los pasos espirituales de su madre, Mame Diarra, como modelo moral.

Regresando a la cuestión de la adquisición de la identidad bayfal aplicada a las mujeres, resulta innegable que la vía "de herencia" para ser yayfal alternativa a la masculina es la de ser "esposa" de un bayfal, y no tanto hija, coherentemente en una comprensión patriarcal del mundo. Como hallamos reseñado en Audrain (2004), muchos hombres bayfal afirman la total dependencia de las mujeres yayfal, en tanto que tales, a los hombres bayfal: solo a través de la transmisión de conocimientos por parte de los bayfal pueden las mujeres convertirse en yayfal; los bayfal mandan sobre 
las bayfal; el marabout de una yayfal es su marido; antes que yayfal, una mujer es esposa de su marido y por tanto le debe todo tipo de obediencia (Audrain 2004). En mi trabajo de campo he recogido apreciaciones similares en distintos varones: se afirma, por un lado, que las mujeres pueden ser yayfal "en pie de igualdad" con la posibilidad masculina análoga; por otro lado, se sentencia que "antes que yayfal son esposas" y que deben trabajo, actividad, obediencia, etc., antes que a nadie, a sus esposos.

Sin embargo, según contaba la informante clave recién citada, una mujer yayfal podía elegir un marabout distinto del marabout de su marido, y con ello practicar un terreno propio y autónomo, de independencia, con respecto al ejercicio y la práctica de su fe como yayfal. No se discutía, pues, que antes que sus obligaciones con la dahira la mujer debía cumplir sus obligaciones como esposa; en ese sentido simbólico o metafórico, sí, "el marabout de una mujer es su marido". Sin embargo, ello se conjugaba con el otro interesante dato de que ambos miembros de un matrimonio puedan tener diferentes marabouts, marcándose un terreno propio para la esposa.

\section{DISCUSIÓN Y REFLEXIONES CONCLUSIVAS}

"...Una de las más pujantes y originales vías esotéricas del islam en el África subsahariana” (Iniesta 2009: 3).

Desde que comencé a interesarme por el muridismo, desde aquella virginidad teórica que mencioné, el bayfalismo fue lo que, con gran diferencia, más poderosamente llamó mi atención: su heterogeneidad genuina, su aparente sincretismo, su (a veces) exuberante estética, la jugosa y estimulante contradicción sobre su condición encontrada en las diferentes interlocuciones, su (a veces) consumo de hachís, los momentos de trance en un kourel, los momentos de fregar cacharros en un magal y cortar cebollas como forma de honrar la idea de lo divino... Así comenzó el interés, y también la confusión a la hora de intentar comprender lo que subyacía al paradójico aluvión de informaciones cruzadas que encontraba aquí y allá sobre lo que era ser, y no ser, bayfal.

En cuanto a las hermenéuticas académicas e interpretaciones de distinto signo, lo que es para algunos flexibilidad es para otros dejación ritual casi rayana en la herejía; lo que es para otros misticismo, es para algunos excesiva sumisión; lo que es para algunos consumo religioso de substancias para acercarse a la divinidad, es para otros ilícita e ilegal conducta licenciosa; en suma, tal riqueza interpretativa y vivencial otorga, en realidad, larga vida al bayfalismo, ya que lo decanta como un movimiento plural, alejado de la homogeneidad que augura los prontos finales; exponente vívido de la amalgama de significados que surge siempre de las experiencias humanas y sociales en general. Como analista, solo puedo maravillarme ante los hallazgos tanto en el campo como en los documentos textuales, que no hacen sino confirmar tal pluralidad.

La etnografía de este trabajo confirma la hipótesis acerca de que el bayfalismo, como movimiento singular en el seno de la Muridiyya, presenta ciertos rasgos que enfatizan su carácter sufí frente a su carácter musulmán, teniendo en cuenta sus prácticas heterodoxas, su agencia independiente e incluso sus vecindades con otras religiones no musulmanas, como el rastafarismo. 
Los resultados hallados durante el trabajo de campo confirman también, de modo sintético que el bayfalismo es una adscripción crecientemente migratoria: muchos senegaleses Murid en la diáspora están "deviniendo" bayfal; en consecuencia, hallamos un empoderamiento progresivo creciente en el bayfalismo, con respecto a su deber de obediencia a la Muridiyya. Tal empoderamiento implica a su vez la adopción de algunos comportamientos y tendencias novedosos y no tradicionales en la diáspora bayfal. Por otro lado, la persistencia de un bayfalismo altamente ortodoxo, tanto en Senegal como en la diáspora, cobra igualmente nueva importancia, acaso como movimiento de contestación al actual proceso de transformación diaspórica.

Tales procesos están dando lugar, igualmente, a la formación de una "opinión oficial" en el núcleo duro de la Muridiyya sobre que el bayfalismo se halla en un proceso progresivo y peligroso de corrupción, especialmente a causa del factor de la migración transnacional; más incluso de lo que lo ha sido siempre: al fin y al cabo, los bayfal "tradicionales" o clásicos en Touba se hallan más fácilmente sometidos al control social, y de un modo novedoso, inédito, debido a la diáspora transnacional. Se refuerza así la defensa de un bayfalismo "puro" y "genuino", manteniéndose una concepción esencialista de la adscripción bayfal, y todo ello no parece sino consolidar la dicotomía entre los "malos" y los "buenos" bayfal, ahora en la versión de los "contaminados" por la cultura occidental, por la migración, y los "originales", basada en la categoría del "exterior" o "extranjero" como un factor de corrupción y peligro.

La circulación de valores murid y bayfal a través de la intensa diáspora migratoria, en este caso en España, da lugar a constantes reinterpretaciones y sincretismos en la vivencia, la experiencia y la cognición incluso de la práctica del bayfalismo. Ello cobra una especial relevancia en el caso analizado de los taalibe murid y, más aún, en los miembros bayfal o los que se unen a ello durante el proceso diaspórico, analizado en nuestro caso de estudio en España y comparado con la literatura actualizada. Repasemos los elementos clave: el bayfalismo representa un grupo singular, con una historia singular, en el seno de la Muridiyya. Actualmente está desarrollando dinámicas específicas que separan a los miembros bayfal de la evolución del resto de murid. En sociedades de migración, los migrantes bayfal encuentran, habitualmente, un modo distinto de practicar su fe e incluso evolucionar a formas culturales de creciente autonomía con respecto a la corriente principal murid. El bayfalismo parece resultar una adscripción particularmente atractiva para las personas no previamente bayfal durante la diáspora migratoria a causa de dos razones principales: 1) el bayfalismo abra un margen amplio de libertad en la práctica de la fe murid, porque presenta un desarrollo creciente en la diáspora, y aparte de las críticas de herejía que llegan desde el statu quo; 2) el bayfalismo ofrece un grupo de apoyo muy fuerte en la nueva sociedad, enfatizando los vínculos cercanos entre los miembros, lo que lo convierte casi en una suerte de "tribu urbana" en un contexto de franca hostilidad y vulnerabilidad para los migrantes; de hecho, el fuerte espíritu comunitario arraigado en la espiritualidad da lugar a una solidaridad estructural, sustitutiva del apoyo familiar en el nuevo contexto. Ello sucede de por sí en las dahiras, pero en los grupos específicamente bayfal parece acrecentarse de modo notable.

En consecuencia de todo ello, parece legítimo hablar de un bayfalismo diaspórico, específicamente migratorio, que presenta una fuerza centrípeta creciente, lo que significa también una resignificación exuberante que claramente hace necesarias ulterio- 
res investigaciones sobre el tema. En ellas, pienso que sería fundamental cuestionar especialmente el interrogante sobre quién tiene el poder para definir el movimiento y quién nombra, precisamente, la ortodoxia, en una tendencia ya de por sí intrínseca y genuinamente heterodoxa.

Lo que sucede en la diáspora Murid/bayfal es precisamente un ejemplo etnográfico que problematiza la idea de "movimiento" o "circulación"; son las condiciones sociales, institucionales e históricas que vehiculan cualquier suceso o proceso identitario, las que pueden explicar el por qué de los hibridismos prácticos y epistemológicos que nos encontramos. Así las cosas, los conceptos de "reencuadramiento" y "refocalización" (Spyer y Steedly 2013: 19) podrían ser útiles para comprender lo que sucede en la diáspora bayfal. En tanto que "reencuadramiento" implica un determinado marco de referencia (conjunto de ideas o asunciones sobre cómo los hechos deben ser evaluados, contemplados o comprehendidos; qué es lo adecuado, incluso lo que está "de moda", y qué no) (Spyer y Steedly 2013: 19), la nueva comprensión diaspórica de qué significa ser bayfal, cómo se ha de habitar el mundo y qué importa y qué no importa, cambia en la medida en que cambia el marco; se "reencuadra" en un contexto distinto; así, por otro lado, "reenfoca" sus intereses y prioridades en otros lugares o con énfasis diferentes, no tanto ya, o no solamente, a los valores de las sociedades receptoras de diáspora (valores en sí mismo a menudo contradictorios y en controversia), sino al nuevo producto híbrido que supone la suma de "lo que se trae" y "lo que se encuentra".

Spyer y Steedly (2013: 17) han descrito bien, pues, esa dialéctica que sucede en los fenómenos globales entre sensación de intimidad global y la sensación persistente de peligro, inestabilidad o impureza incluso, que da lugar a tales productos híbridos. En el caso de la cultura diaspórica bayfal, las transformaciones y resignificaciones descritas pueden ser comprendidas desde esta noción "polivalente" de Spyer y Steedly (2013) y la problemática que describen sobre las "imágenes en movimiento", generadas por la misma circulación y la condición espectacional de los hechos sociales, así como la relevancia del lugar preciso donde se articula el "valor existencial" de las categorías humanas (ibid:: 16).

Finalmente, en el presente solo es posible concluir la rutilante pluralidad del movimiento, que augura un largo y complejo futuro, ya que lo inflexible "se rompe" pronto. Esta interesante capacidad de adaptación, de mimetismo, de sincretismo en todos los aspectos que presenta el bayfalismo, implica precisamente la "vida" del movimiento, su espontaneidad arraigada en el "mundo de la vida"; que nunca fue un proyecto cerrado en la mente de un ideólogo sino una experiencia colectiva e individual, en creciente y constante cambio evolutivo.

\section{BIBLIOGRAFÍA CITADA}

Aardal, Cecilie. 2010. "Living youth, becoming somebody: life in Urban Dakar". Tesina de Master in Social Anthropology, Universidad de Oslo. Disponible en: <https://www.duo.uio.no/bitstream/handle/ 123456789/16171/MASTEROPPGAVENxferdig.pdf?sequence=1>. Fecha de acceso: 02 mar. 2016.

Audrain, Xavier. 2002. "Baay-Fall du temps mundial: individus modernes du Senegal. Des dynamiques de construction de sujets individuels et d'invention d'une modernité véhiculées par l'originale communauté islamique des Baay-fall». Memoria de DEA, París 1- La Sorbona, U.F.R. 11. 
Audrain, Xavier. 2004. "Devenir Baay Fall pour être soi”. Politique africaine 94: 149-165.

Babou, Cheikh Anta. 2002. "Brotherhood solidarity, education and migration: the role of the Dahiras among the Murid Muslim community in New York". African Affairs 101: 151-170.

Bocci, Paolo. 2010 "Identity in its making: playing the difference in the music of Baay Fall". Tesis de Master of Arts in Anthropology, Universidad de North Carolina, Chapel Hill. Disponible en: <https:// cdr.lib.unc.edu/indexablecontent?id=uuid:6b9b5336-8198-4a55-991a-770bef05ae9e\&ds=DATA_FILE >. Fecha de acceso: 02 mar. 2016.

Brenner, Louis. 2005. West African Sufi. The religious heritage and spiritual search of Cerno Bokar Saalif Taal. Londres: Hurst \& Co.

Cerrolaza Molina, Erika. 2014. "Nuevas formas de religiosidad y reelaboraciones identitarias". Revista de Estudios Internacionales Mediterráneos 16: 1-11.

Costa Dias, Eduardo. 2009 "Cofradías musulmanas y movimientos de Da'wa: dos concepciones del Islam en África occidental", en Ferran Iniesta Vernet (ed.), El islam del África negra: 39-59. Barcelona: Bellaterra.

Coumba Diop, Mouma. 1981. "Functions and Activities of the Murids' Urban 'Dahira' in Senegal". Cahiers d'Études Africaines 21(81/83): 79-91.

Crespo Ubero, Rafael. 2006. "Participación y asociacionismo senegalés. De la visibilidad a la conexión transcontinental", en Mercedes Jabardo Velasco (ed.), Senegaleses en España. Conexiones entre origen y destino: 132-142. Madrid: Ministerio de Trabajo y Asuntos Sociales.

Cruise O'Brien, Donald B. 1969. "Le talibé mouride: Étude d'un cas de dépendance sociale". Cabiers d'Études Africaines 9(35): 502-507.

Cruise O'Brien, Donald B. 1970. "Le talibé mouride: La soumission dans une confrérie religieuse sénégalaise". Cahiers d'Études Africaines 10(40): 562-578.

Diouf, Mamadou y Steven Rendall. 2000. "The Senegalese Murid trade diaspora and the making of a vernacular cosmopolitanism". Public Culture 12(3): 679-702.

Ferrándiz Martín, Francisco. 2011. Etnografías contemporáneas. Anclajes, métodos y claves para el futuro. Anthropos/SXXI: Barcelona.

Gómez, Mayte. 2006. "El barrio de Lavapiés, laboratorio de interculturalidad". Dissidences. Hispanic Journal of Theory and Criticism. Disponible en: <http://digitalcommons.bowdoin.edu/cgi/ viewcontent.cgi?article=1023\&context=dissidences $>$. Fecha de acceso: 05 mar. 2016.

Guèye, Cheikh. 2008. "Touba: territorio ideal y lugar de retorno producido por los murid". Nova África 22: 59-75.

Guèye, Cheikh. 2009. "Del lugar común a los 'lugares momentos': la cofradía muride y sus nuevas fronteras", en Ferran Iniesta (ed.), El Islam del África negra: 91-114. Barcelona: Bellaterra.

Hannerz, Ulf. 1996. Transnational Connections: Culture, People, Places. Londres: Routledge.

Iniesta, Ferran. 2009. "Mil años de islam negroafricano", en Ferran Iniesta (coord.), El islam del África negra: 15-38. Barcelona: Bellaterra.

Jabardo, Mercedes. 2006. Senegaleses en España. Conexiones entre origen y destino. Madrid: Ministerio de Trabajo y Asuntos Sociales.

Kane, Ousmane. 2011. The homeland is the arena. Religion, transnationalism, and the integration of Senegalese immigrants in America. Oxford: Oxford University Press.

Massó Guijarro, Ester. 2012a. "La figura del marabout: ¿dominación o emancipación en la diáspora migratoria murid?». Astrolabio. Revista Internacional de Filosofía Política 13: 287-295.

Massó Guijarro, Ester. 2012b. "Cosmopolitismo hoy: la cofradía murid y la comunidad mestiza". Intersticios. Revista Sociológica de Pensamiento Crítico 6-2. Disponible en: <http://www.intersticios.es/ article/view/10098>. Fecha de acceso: 02 mar. 2016.

Massó Guijarro, Ester. 2013a. "La dahira de Mame Diarra en la diáspora: ¿un desafío al patriarcado murid?". Revista de Dialectología y Tradiciones Populares LXVIII(1): 125-144.

Massó Guijarro, Ester. 2013b. "A través del espejo, entre la cámara y el alma: migración senegalesa en el objetivo, debates mestizos en la Universidad de Granada". Dilemata 12: 311-327.

Massó Guijarro, Ester. 2013c. "Comunidades cosmopolitas de interacción en el barrio de Lavapiés: superando el nacionalismo metodológico". Migraciones Internacionales 7-2: 71-100.

Massó Guijarro, Ester. 2014. "Baye-Faal in Senegal, Baye-Faal in Lavapiés, Baye-Faal in the Sacromonte Caves: Diasporic Transnationalism of a Sufi Heterodoxy". The Annual Review of Islam in Africa 12(2): $25-30$. 
Mbacké, Khadim. 2005. Sufism and religious brotherboods in Senegal. Princeton: Markus Wiener Publishers.

Mbaye, Lo y Aman Nadhiri. 2010. "Contextualizing "Muridiyyah" within the American muslim community: perspectives on the past, present and future". African Journal of Political Science and International Relations 4-6: 231-240.

Mbow, Sheik B. 2000. La voie Baye Fall. Maam Cheikh Ibrabima Fall ou la voie du dedans. Ginebra: Impresión privada.

Moreno, Susana. 2007. Aquí y allí, viviendo en los dos lados. Los senegaleses de Sevilla, una comunidad transnacional. Sevilla: Junta de Andalucía, Estudios y Monografías.

Pezeril, Charlotte. 2007. "The evolution of Moslem legitimacy's frontiers in Senegal". Comunicación en la II European Conference on African Studies, Leiden.

Pezeril, Charlotte. 2008a. Islam, mysticisme et marginalité: les Baay Faal du Sénégal. París: L'Harmattan.

Pezeril, Charlotte. 2008b. "Histoire d'une stigmatisation paradoxale, entre islam, colonisation et autoétiquetage : les Baay Faal du Sénégal”. Cabiers d'études africaines 4(192): 791-814.

Pezeril, Charlotte. 2010. "L'anthropologue "insouffisant»: implication du corps et esprit de la voix en pays Baay Faab. Social Compass 57(4): 449-463. Disponible en: <http://scp.sagepub.com/content/ 57/4/449.full.pdf>. Fecha de acceso: 02 mar. 2016.

Piga, Adriana. 2003. L'islam in Africa. Sufismo e jibad fra storia e antropologia. Roma: Bollati.

Riccio, Bruno. 2008. "West African Transnationalisms Compared: Ghanaians and Senegalese in Italy". Journal of Ethnic and Migration Studies 34(2): 217-234.

Riccio, Bruno. 2011. "Rehearsing Transnational Citizenship: Senegalese Associations, Co-development and Simultaneous Inclusion". African Diaspora 4: 97-113.

Roberts, Allen F., Mary Nooter Roberts y Gassia Armenian. 2003. "Apostle of hard work. Sheikh Ibra Fall and the Baye Fall movement", en VVAA (eds.), A Saint in the city: Sufi arts of urban Senegab: 109-121. Los Ángeles: Universidad de California Los Ángeles.

Rosander, Eva Evers. 2000 "Money, marriage and religion: Senegalese women traders in Tenerife, Spain", en Thomas Salter y Kenneth King (eds.), Africa, Islam and development: Islam and development in Africa-African Islam, African development: 167-191. Edimburgo: Universidad de Edimburgo.

Rosander, Eva Evers. 2006. "Sacralizing Hotels in Spain: Murid Marabouts in motion". El Awraq, XXIII: 131-152. Madrid: Dirección General de Relaciones Culturales y Científicas. Disponible en: <http:// www.aecid.es/galerias/publicaciones/descargas/AWRAQ_VOL_XXIII_2006.pdf>. Fecha de acceso: 02 mar. 2016.

Samson, Fabienne. 2009. "Islam, protest, and citizen mobilization. New Sufi movements", en Mamadou Diouf y Mara A. Leichtman (eds.), New perspectives on Islam in Senegal. Conversión, migration, wealth power, and femininity: 257-272. Nueva York: Palgrave McMillan.

Savishinsky, Neil J. 1994. "The Baye Faal of Senegambia: Muslim Rastas in the Promised Land?" Journal of the International African Institute 64(2): 211-219.

Seck, Abdourahmane. 2010. La question musulmane au Sénégal. Essai d'anthropologie d'une nouvelle modernité. París: Karthala.

Skali, Faouzi. 1993. La vía sufí. Madrid: Ibersaf Editores.

Skali, Faouzi. 2006. Jesús en la tradición sufí. Madrid: Ibersaf Editores.

Sow, Papa. 2004. "Prácticas comerciales transnacionales y espacios de acción de los senegaleses en España", en Angels Escrivá y Nuria Ribas (eds.), Migración y desarrollo. Estudios sobre remesas $y$ otras prácticas transnacionales: 235-254. Córdoba: CSIC.

Spyer, Patricia y Mary M. Steedly,. 2013. "Images that move", en Patricia Spyer y Mary M. Steedly (eds.), Images that Move: 3-39. Santa Fe: School for Advanced Research.

Suárez Navaz, Liliana. 2008. "La perspectiva transnacional en los estudios migratorios. Génesis, derroteros y surcos metodológicos", en Jordi García Roca y Joan Lacomba (eds.), La inmigración en la sociedad española. Una radiografia multidisciplinar. 771-794. Barcelona: Bellaterra.

Sylla, Assan. 1994. La philosophie morale des Wolof. Dakar: Universidad de Dakar Cheikh Anta Diop.

Fecha de recepción: 11 de mayo de 2015

Fecha de aprobación: 15 de septiembre de 2015 